* Cómo citar este artículo: Gálvez Granada, J. (2020). Estética de la destrucción: los objetos materiales en Viaje al interior de una gota de sangre de Daniel Ferreira. Estudios de Literatura Colombiana 47, pp. 189-206. DOI: https://doi.org/10.17533/udea.elc.n47a10

1 https://orcid.org/0000-0003-2591-1794 jgalvezgg@gmail.com

Universidad de Buenos Aires, Argentina
Editores: Andrés Vergara Aguirre, Christian Benavides Martínez, Valentina Noreña Gómez

Recibido: 05.02.2020

Aprobado: 11.05.2020

Publicado: 23.06.2020

Copyright: $(02020$ Estudios de Literatura Colombiana. Este es un artículo de acceso abierto distribuido bajo los términos de la Licencia Creative Commons AtribuciónNo comercial - Compartir igual 4.0 Internacional

\section{ESTÉTICA DE LA DESTRUCCIÓN: LOS OBJETOS MATERIALES EN VIAJE $A L$ INTERIOR DE UNA GOTA DE SANGRE DE DANIEl FerReira*}

\author{
The Aesthetics of Destruction: \\ Material Objects in Viaje al interior DE \\ unA Gota DE SANGRE by Daniel Ferreira
}

Jessica Gálvez Granada ${ }^{1}$

Resumen: este artículo reflexiona sobre la función simbólica de los objetos materiales en la novela Viaje al interior de una gota de sangre de Daniel Ferreira. Se parte de la carencia de abordajes para la materialidad en literatura para proponer categorías de análisis con las cuales leer los objetos materiales. Los aportes de W.J.T. Mitchell son indispensables para pensar el carácter visual que hace posible la formulación de estas categorías. El análisis de la novela desde la perspectiva material ilumina relaciones inter y extratextuales que se corresponden con cuestiones de la agencia del objeto y la memoria nacional.

Palabras clave: Daniel Ferreira; objeto material; metarrepresentación; literatura colombiana.

\begin{abstract}
This article reflects on the symbolic function of material objects in Daniel Ferreira's novel Viaje al interior de una gota de sangre. It starts with the lack of useful approaches to materiality in literature to put forward some analysis categories with which to read material objects. The contributions of W.J.T.Mitchell are indispensable to think the visual character responsible for the formulation of these categories. The novel analysis from the material perspective enlightens inter and extra-textual relationships that correspond to matters of the agency of the object and of national memory.
\end{abstract}

Keywords:Daniel Ferreira; material object; metarepresentation; Colombian literature. 
Uno de los temas centrales de los últimos años en los estudios culturales se ha venido desarrollando alrededor de la influencia que la materialidad ejerce sobre distintas esferas de la sociedad. Dentro de los estudios literarios, el análisis del objeto material es apenas una inquietud emergente. El problema de la materialidad en la literatura permea instancias que superan los lindes de la verosimilitud estética, por lo cual se hacen necesarios nuevos abordajes que se pongan al corriente con las preocupaciones del momento. Cuando hablo del objeto material me refiero a los objetos que una narración ubica alrededor de los personajes, ya sea para ambientar una escena o para posibilitar o interferir con los sucesos narrados. La materialidad en el relato supera la función única de la descripción y adopta una posición activa y significante para el todo narrativo en tanto los objetos son "repositorios de plenitud semántica"(Brown, 2015, p.13). Y si bien los objetos se han presentado como determinantes en las narraciones desde hace varios siglos, recién en los últimos años una serie de tímidas aproximaciones se han animado a considerar el objeto material en tanto elemento de análisis.

Sobre tales supuestos parte el trabajo de investigación del cual se deriva este artículo sobre cómo el objeto material se inserta en obras de literatura colombiana contemporánea y estudia sus manifestaciones y funcionamiento tanto dentro como fuera del texto. En esta ocasión, discutiré las configuraciones del objeto material en la narrativa del emergente escritor colombiano Daniel Ferreira. Su nombre no causa aún demasiado eco, pero sus novelas se abren paso en el campo de la narrativa latinoamericana contemporánea por su potencia poética y su abordaje renovado y crítico de la temática eterna e inagotable que es la violencia colombiana. $Y$ es que su proyecto, denominado Pentalogía (infame) de Colombia intenta congelar cinco momentos específicos de la historia nacional para entender, una vez más, las razones históricas de nuestros actuales males. Esta obra, que comprende cuatro novelas publicadas y otra inédita, se sumerge en las profundidades de un amplio rango de historias tocadas por la violencia centenaria que ha desgarrado al país e intenta retratar los dramas más humanos en contraste con la barbarie.

Lo que posibilita leer su obra desde la perspectiva material es el amplio sustrato de objetos que habitan esta narrativa. Inicialmente, visitaré los presupuestos teóricos y conceptuales centrales para después ejemplificar en la novela Viaje al interior de una gota de sangre (2011) la función semántica que detenta el objeto material, 
y simultáneamente analizaré los significados inscritos en la novela por cuenta de su contenido material. Esta aproximación resulta particularmente provechosa para acercarse a la narrativa colombiana (aunque no exclusivamente) porque devela los rastros físicos y evidentes de los hechos que narra y constituye un puente directo entre el mundo ficcional y la realidad empírica.

\section{Cómo pensar los objetos materiales en la narrativa actual}

Para aclarar el funcionamiento de los objetos materiales en el análisis literario que propongo, es preciso primero explicar su estatuto como imágenes. En este sentido, los aportes del teórico W.J.T. Mitchell son fundamentales para entender la facultad eminentemente visual del objeto material en literatura. Sus estudios alrededor de la relación inherente entre palabras e imágenes ponen de manifiesto la cercanía incontestable entre ambas y, para el caso del análisis literario, sirven de base para pensar el objeto material en su esfera visual. Las imágenes son "los objetos representacionales concretos sobre los cuales los sentidos aparecen", que se traducen en esta visión al pensar en "las maneras en que los textos actúan como imágenes, o incorporan prácticas pictóricas y viceversa" (Mitchell, 1994, p. 4, traducción propia). La acción activa del representar y la acción pasiva del imaginar configuran una relación dialéctica en la cual la imagen se posiciona frente al receptor e inscribe su significado. La propuesta de Mitchell reconoce el poder que las imágenes tienen sobre los modos de vida y propone una visión crítica de la representación al partir de la imagen como punto central, además de posibilitar la comprensión de la aparición de objetos materiales sobre las representaciones como imágenes, que insertan en ellas sentidos particulares.

Una de las manifestaciones de la relación entre imágenes es aquella dada en lo que Mitchell llama metaimágenes, o "imágenes que se refieren a sí mismas o a otras imágenes"(p. 35). De acuerdo con este autor,

Se requiere un sentido de espacios y niveles anidados y concéntricos para estabilizar una metaimagen [...]. Incluso una imagen-dentro-de-una-imagen que duplica el sentido que lo enmarca (el efecto de puesta en abismo) puede, en principio, mantener sus niveles, límites y marcos distintos. Considere un dibujo que muestra un hombre pintando una imagen de un hombre pintando una imagen 
de un hombre... etc. La regresión infinita de simulación, duplicación y repetición no desdibuja la distinción de niveles [...]. Cada nivel [está] claramente distinguido como un afuera para otro adentro. [...] una imagen acerca de sí misma, una imagen que se refiere a su propia elaboración (p. 42).

Es en esta luz que pretendo proponer una lectura de la novela en cuestión con el objeto material como centro del análisis. En el marco de la noción de metaimagen que propone Mitchell, donde se hallan autocontenidas distintas formas de representación, encuentro que los objetos materiales son los límites donde se hace discernible esta cualidad en obras literarias que no necesariamente contienen una puesta en abismo en la acepción más común de la expresión. Pensar que en vez de un hombre pintando la imagen de un hombre, existe un objeto que contiene otro objeto abre la posibilidad para admitir un modo de lectura en el cual el potencial de significación se multiplica ad infinitum.

Tal es el objetivo de este modo de lectura que he denominado la "Estética de la Destrucción": enfatizar la función del objeto material que imprime sus sentidos específicos sobre todas las esferas de la realidad, incluida la literatura. Este es un aparato de categorías que permiten clasificar y pensar los objetos materiales en función de su estatuto como imágenes. De esta forma, el objeto material se piensa como una parte del entramado semántico de la obra literaria y se clasifica en función de su cualidad visual. Es decir, para posibilitar un análisis material de un hecho literario, ante todo es necesario apreciar a los objetos dentro de la imagen mental que una narración proyecta. De la misma manera en que la mente "imagina” descripciones de personas o lugares, también lo hace con ciertos arquetipos de objetos materiales con los que la obra construye significado. Lo disruptivo de esta propuesta constituye el abandono del actuar humano e incluso de la acción narrada en pos de permitir espacio a los sentidos que se comunican mediante los objetos materiales.

Las particularidades que dan nombre a esta propuesta de lectura atienden, por una parte, a la ya mencionada cualidad visual de los objetos para los cuales es necesario establecer conceptos de naturaleza estética; y, por otra, a que las temáticas en las cuales se desarrollan los argumentos de las narraciones - ya que la justificación inicial de esta propuesta se posiciona sobre una sustitución de la atención analítica desde el sujeto humano hacia el objeto material - involucran dinámicas de destrucción. De esta 
manera, el modo de análisis que propongo se emparenta con el concepto de destrucción de Heidegger en tanto implica una ruptura con las formas tradicionales del análisis literario en pos de vías alternas para buscar el significado inscrito en las obras. Si se quiere observar la agencia y el poder del objeto material, primero que todo el sujeto humano ha de aparecer desplazado del centro temático de la obra. Con lo anterior no quiero decir que no exista la presencia ni la agencia del sujeto humano en las novelas, sino que en ellas se abre un lugar para observar el actuar del objeto fuera de la sombra del sujeto; la destrucción inserta hilos narrativos donde la literatura se pregunta por el fin de la vida, por el lugar del ser humano frente a la muerte, y por el lugar del objeto frente a la muerte del sujeto humano. De la misma manera en que Heidegger se posiciona frente a la fenomenología de su maestro, la Estética de la Destrucción "no evacúa o prescinde del cuerpo de la tradición, sino que busca reavivarla” (Velázquez, 2015, p. 333).

Lo anterior quiere decir que existen varios tipos de objetos materiales que intervienen en una narración y que pueden registrarse por la palabra literaria, con o sin mediación del discurso representativo visual. La materialidad se presenta específicamente en dos niveles: uno mediado por la percepción sensorial y otro por la representación artística. Todo objeto que rodea, facilita o delimita la experiencia humana dentro de la narración lo denomino objeto empírico, en tanto es evidente para los sentidos. Dado que la imagen se da a través de distintos recursos, el objeto empírico puede ser visual o textual. Este es el tipo de objeto más común en cualquier narración, y es justamente el tipo de objeto que el análisis estructuralista ha pasado por alto en sus valoraciones de la descripción como procedimiento literario. Una pequeña revisión a la producción literaria contemporánea bastará para comprender que la materialidad hace mucho tiempo dejó de servir únicamente como telón de fondo de las acciones narradas o de obtener su valor en relación con los destinos finales de los sujetos humanos. Las relaciones humanas con su entorno son cada vez más complejas, la literatura se adapta a ello incluso sin consciencia de esto, y es preciso contar con herramientas para leerlas.

De la misma manera, atendiendo de nuevo a la noción de metaimagen que propone Mitchell, existe un fuerte sustrato de obras literarias que contienen en sí objetos de naturaleza representativa. Llámense estos dibujos, pinturas, fotografías, videos, diarios, libros, cuadernos, se insertan en la narración de la misma manera 
que los objetos empíricos, con la salvedad de que en sus fronteras se incluyen capas subsiguientes de representación que incrementan el coeficiente representativo del texto. Estos son objetos representacionales que pueden ser de naturaleza pictórica o literaria y a su vez pueden contener en sus límites más objetos empíricos. Las interacciones entre unos y otros estarán dictadas por las leyes de cada obra literaria, pero encuentro que estos son los presupuestos conceptuales mínimos, útiles para resolver la mayor cantidad de instancias materiales.

Estos tipos de objetos intervienen en las narraciones de diferentes maneras, y confieren distintos tipos de significado. Dentro de las obras, detentan agencia y contribuyen a erigir la realidad ficcional; y fuera de ellas, los objetos materiales codifican declaraciones estéticas y posiciones críticas frente a sus condiciones de producción. De esta manera, se hace evidente la importancia de considerar como necesario un modo de lectura que abarque todos los sentidos que allí se inscriben y que con estas categorías se hacen claros para una mirada atenta. El trabajo de esta investigación ha consistido en dilucidar los tipos de objetos materiales, sus características y las formas en que intervienen para construir sentido literario.

Para el caso específico de este artículo, el lugar donde explicaré el funcionamiento del objeto material es en la novela del santandereano Daniel Ferreira, Viaje al interior de una gota de sangre, que ganó el Premio Latinoamericano de Novela Alba Narrativa 2011. Esta novela inserta motivos estéticos para comunicar sentidos literarios a través de objetos materiales de carácter visual y desarrolla un argumento que avanza hacia una terminación abrupta de las funciones vitales del ser humano. En esta combinación de elementos, la obra de Ferreira despliega un inventario de objetos materiales de la más plural naturaleza, que evidencia de forma directa la destrucción del sujeto y donde las interpretaciones estéticas también entran en juego. Sobre estas bases mínimas se desarrolla el análisis de la novela de Ferreira, que narra una situación de guerra ensamblada sobre una aguda percepción y representación de los objetos materiales que resultan determinantes para comprender los significados que el libro configura.

Viaje al interior de una gota de sangre ofrece una vista panorámica de una masacre paramilitar en un pueblo anónimo de Colombia. En palabras de Catalina Holguín (2015), 
La novela inicia con una matanza oficiada por una parranda de encapuchados en la plaza de un pueblo en medio de un reinado local. "Tres mil casquillos de balas disparadas y medio centenar de cuerpos después", la novela vuelve a iniciar. Como si asistiéramos a un acto de resurrección, la novela recorre de nuevo, personaje a personaje, la vida de cada uno hasta llegar al momento exacto anterior a su muerte. A través de todas las historias se adivina más que una historia personal: en cada personaje se multiplica y se refleja la historia de un pueblo que termina ajusticiado, una tarde de fiesta, por la violencia paramilitar (s.p).

Los conflictos que se venían desarrollando desde mitad del siglo xx estallan en la década de los ochenta por la expansión del narcotráfico, lo cual intensificó los dramas políticos y sociales. Ambientada en esta década, la novela retrata casi todos los tropos relacionados con el contexto histórico del país en ese momento: la Violencia pasada, la presencia de grupos paramilitares en los cascos urbanos, los paros campesinos, los "patrones" prescribiendo los modos de vida de las comunidades, el cuerpo femenino como objeto comercial, la Teología de la Liberación, las masacres perpetradas por el Ejército y la presencia de grupos guerrilleros son ejemplos de hechos reales que Ferreira incluye en su novela. La lucha contra el olvido, que en Colombia ha sido política de Estado, se convierte en pugna personal en el trabajo de este escritor. Su narrativa se resiste a la negación del pasado y las múltiples violencias que ha sufrido el país desde sus inicios. Frente a la pregunta de por qué insistir en narrar la guerra en Colombia, la respuesta más sencilla sería que la literatura de Daniel Ferreira no es más que un síntoma de la no superación de los conflictos no solo en lo más evidente como lo militar, sino en lo social.

\section{La agencia del objeto material sobre la narración}

La plaza central del pueblo se encuentra atestada de personas. "Son las 5:50 de la tarde del 23 de septiembre, y en ese mismo instante, en la plaza central del caserío, los pobladores alistan la verbena y coronación de la reina popular" (Ferreira, 2011, p. 10). Hay una tarima, juegos, comida, pista de baile y mesas para que la gente pueda disfrutar con gusto del evento del día. En instantes una caravana de encapuchados entrará a abrir fuego contra la población. El primer capítulo narra la escena general de la masacre y hace uso de una masa de objetos materiales y personajes en apariencia efímeros para dar profundidad a la escena que relata. 
A lo largo del texto, las situaciones identificadas en el apartado anterior se presentan al lector por medio de la representación material. El objeto empírico textual funciona para la lógica de la novela como la herramienta que permite hablar de las dinámicas sociales propias de la comunidad que representa sin la necesidad de extenderse en historias del pasado, y funciona como un marco de referencia material para complejizar a los personajes secundarios cuyo destino es morir. Este capítulo reúne las personalidades que no le serían ajenas a nadie por la generalidad de sus configuraciones; establece también vínculos con los lectores en tanto proyecta sobre la novela referentes visuales de la cultura de proveniencia, incluso sus paradojas:

\begin{abstract}
La señora Edelmira Peñaranda, una mujer de sesenta años que vive postrada en una silla a media cuadra del parque central [...], permanece en la mecedora mientras repasa la Biblia entre sus rodillas vanas [...]. La señora Edelmira levanta la cabeza y descubre, ajustándose el óvalo de largas distancias de sus anteojos bifocales, la camioneta que se acerca. Una repentina palpitación le hace erguir la espalda de la silla y cruzar palabras con su hijo que está en la sala:
\end{abstract}

-Patricio: ahí viene un carro lleno de gente armada.

Patricio deja de aceitar la pistola que heredó de su padre y que suele pulir todas las tardes, asoma al balcón y ve los vidrios ahumados y los hombres armados y con capuchas sobre el platón del carro y dice: "ya vuelvo" (Ferreira, 20II, pp. 18-19).

Este ejemplo, a modo de corolario del funcionamiento del objeto empírico textual en la novela, estructura toda la acción. Por una parte, describe a madre e hijo a través de sus objetos de fetiche: la mujer con su biblia y el joven con su arma hablan de valores que se pasan por sucesión, que prefiguran una manera de estar en el entorno y a cuyo cuidado se abocan. Por otra parte, la aprehensión de los hechos por parte de los mismos personajes se da mediada por el uso del objeto. Los anteojos habilitan ver la camioneta; las armas y las capuchas permiten entender la gravedad del asunto. Así, el objeto material ejerce su agencia en varios niveles y, al mismo tiempo, configura los conflictos morales que pueden ser propios de una fábula como esta: en una misma casa conviven biblias y pistolas; en un mismo pueblo, una fiesta y una masacre. La función del objeto material, aparte de ubicar espacial y arquetípicamente los personajes, también es la de sintetizar las dinámicas sociales en las que se desenvuelve un relato como aquel, del país en el que una pistola es un objeto doméstico. En este ejemplo es importante ver 
que la narrativa actual se maneja en códigos distintos de aquellos que proponían los teóricos del estructuralismo al construir obras en las cuales la descripción y en especial el detalle encarnado en el objeto material contribuyen al sentido integral de una obra.

Por otra parte, hay una esfera de la manifestación de la agencia del objeto empírico que se emparenta con el concepto de actante de la teoría literaria (Bal, 1985). En este sentido, un actante es aquel elemento de la narración que causa o experimenta un suceso, y en Viaje al interior de una gota de sangre los objetos empíricos que registra la palabra funcionan (al nivel sintáctico del texto) detentando acciones como lo haría el sujeto de una oración. En esta novela observo una incidencia evidente, que está dada por el mismo verbo de la oración. Esta sería, si se quiere, la versión corta y directa de lo que la Estética de la Destrucción busca: un lugar desde donde se habilite pensar las formas en que un texto infunde significados a través de objetos materiales: un lugar donde los objetos hacen. A pesar de que la trama de la novela es una masacre perpetrada por humanos, la narración configura a algunos personajes desde las sombras de la acción de los objetos, lo cual es sumamente significativo porque tiene relación con las formas de delineamiento del sujeto dentro del relato. En los siguientes ejemplos, la narración configura el objeto como un ente activo: "Un barrido de ametralladora silenció a los cinco músicos”(Ferreira, 2011, p. 22); “Un solo disparo que se cuela en la cintura de la anciana y Matilde Sopetrán dobla su talle, cierra los ojos y muere casi al instante sobre las hierbas secas y el mortero de macerar cominos” (p. 23); “Machetes de doble filo y mazos de guayacán golpeaban las puertas para instar a todo el pueblo a rebelarse contra el régimen” (p. 80).

Es posible ver ahora un patrón que va emergiendo. Los objetos materiales toman la posición activa en las oraciones y ejecutan las acciones fatales contra el resto de los personajes. Esta es una violencia del objeto, aunque evidentemente esté enmascarando a un sujeto humano. Ejemplos como los anteriores son abundantes en la novela, pero el objeto no solo efectúa acciones letales, también se configura de formas menos agresivas: "Fue su perfume de aceite de almendras lo que me robó la tranquilidad y la niñez para siempre" (p. 36); "Pero entonces suena una ráfaga y la bota que oprimía mi nuca contra el piso de pronto levanta su peso de hierro" (p.38); "Solo la mechera que usó el padre para encender enseguida el cigarro bastó para dibujar su rostro asediado por la oscuridad" (p. 128). 
El autor juega con ellenguaje para privilegiar el objeto como la fuente de la acción, en medio de un giro poético que busca inscribir la violencia en un registro alterno. Es una decisión estética dejar que el lugar de la performatividad sea ocupado por un objeto inanimado, ya que, para la calidad de la prosa de Ferreira, resulta insuficiente presentar ciertas acciones como simples y llanas, susceptibles de ser pasadas por alto. Hay un engrandecimiento del pequeño acto, del detalle, que solo es visible cuando se saca del lugar activo al sujeto humano. En este sentido, el objeto se anima y ejerce sobre la totalidad de la narración una inversión de los roles hegemónicos de la representación: moviendo la atención lejos del gran acontecimiento causado por el humano hacia el milisegundo en que la materialidad da cuenta de los resquicios a los que no llega la narración macro. El objeto como actante reclama atención sobre las acciones secundarias, casi irrepresentables, escurridizas a la palabra. Los matices interpretativos que la aproximación al objeto permite son especialmente útiles al pensar los modos de inscripción de significado en la literatura colombiana, pues resulta una operación radicalmente distinta a la clásica novela de la Violencia, por ejemplo.

Hay otra respuesta a los interrogantes de qué efectos provoca el objeto material como el actante de una oración y qué tiene que ver con la instancia ideológica de la enunciación desde la materialidad. Los personajes que muchas veces no tienen nombre aparecen en la novela como sus cosas. Particularmente, los perpetradores de las acciones letales se muestran desdibujados por el actuar del objeto. Las acciones que ellos ejecutan no son propias: son de las cosas que tienen. Hay una intención autoral muy notoria en la performatividad de los objetos materiales porque en este universo una bala atraviesa, una bota oprime, una ametralladora silencia o un aceite arrebata la inocencia. De entrada, definir un personaje desde los objetos de su entorno pareciera aplicar un borramiento de la identidad de una persona, en contraste con la concreción de su entorno material. Esta concreción crea un desvanecimiento del personaje sobre quien recae o quien ejecuta las acciones. ¿Qué crea esto? ¿Por qué borrar la identidad de un personaje? Una posible interpretación de esto tiene que ver con la esfera crítica de la obra de Ferreira.

En números, la guerra en Colombia ha tocado a millones de personas, y en el proyecto narrativo del autor, singularizar es excluir. Hay tantas personas a las que la guerra ha afectado que especificar los rasgos de uno es restarle identidad al resto. Hablar de ellas mediante los objetos que los circundan es una forma de dejar abierto 
un espacio para las numerosas víctimas y victimarios anónimos, para que pueda ser ocupado por cualquiera. La novela enfatiza sus personajes desde el objeto material como un síntoma de que cuando se trata de los actores del conflicto, no hay caras. ${ }^{1}$

Hasta ahora, se ha podido vislumbrar el potencial analítico que el objeto empírico habilita para leer esta obra; son pocos los ejemplos de este tipo que he podido incluir en este apartado, pero resultan una muestra significativa de los significados que esta logra inscribir sobre el lector. Abrir la puerta a maneras de leer que presten especial atención a los modos de funcionamiento del objeto material solo puede resultar benéfico, máxime en el momento histórico en que toda la experiencia se tamiza por un filtro material.

\section{La memoria en disputa}

A diferencia de los objetos empíricos que ejercen agencia sobre los hechos narrados, es alrededor de los objetos representacionales que la obra construye sus preocupaciones más profundas. En el caso de la novela de Ferreira, los objetos representacionales se ubican sobre las historias de los personajes principales y llegan al centro de la reflexión que el autor pretende establecer con Viaje. El problema que Daniel Ferreira intenta conjurar es el de la memoria, de "Cómo escribir sobre la violencia cuando hemos hecho del olvido uno de nuestros insumos esenciales" (Guerrero, 2018, s.p). Esta es la pregunta que el autor pone frente al lector cuando construye sus personajes principales. La lectura de estos mediante la Estética de la Destrucción ayuda a esclarecer la importancia que adquiere la memoria nacional para este relato en relación con los vínculos que sostenemos con la materialidad.

El primer ejemplo de esto es la historia de Delfina. Adolescente, talentosa nadadora de río, espera con ansias el momento de abandonar el pueblo donde se siente atrapada, abandonada a su suerte luego de la desaparición de su padre contrabandista en medio de las montañas. Ella, que pudo ser una deportista exitosa si hubiera tenido la posibilidad de salir del pueblo, se lamenta de su suerte e intenta encontrar consuelo en el recuerdo de su padre:

1 Esta operación se puede encontrar en otro lugar de la narrativa colombiana contemporánea. En Los ejércitos (2007), de Evelio Rosero, un pueblo es tomado por fuerzas anónimas que siembran el terror, matan, desaparecen y terminan por dejarlo deshabitado. La particularidad de este terror es la indeterminación de la procedencia de estos ejércitos que hostigan el pueblo. La novela no menciona si se trata de grupos guerrilleros o paramilitares, y en esto configura una postura frente a la pluralidad de agentes de terror y el lugar de vulnerabilidad de las comunidades rurales. 
Delfina camina hasta el ropero y saca un viejo álbum de fotos con la tapa desportillada. Con precaución logra zafar la vieja portada de los anillos sujetadores y contempla con interés la primera foto: un bebé suspendido en una tinaja con agua de flores de caléndula, que mira al fotógrafo a través de la piel del agua. [...] — Si estuvieras vivo - murmura (Ferreira, 20II, p. 50).

El álbum de fotos donde la joven va a buscar los momentos de felicidad se configura como el único residuo material que contiene las imágenes de lo que fue y lo que pudo ser su vida si la violencia no le hubiera arrebatado las oportunidades. El álbum es un objeto empírico que contiene objetos representacionales y su descripción es una premonición de los sentidos que para la novela implican las fotografías. El conflicto de Delfina es el recuerdo, cómo lidiar con lo que ya se perdió a la luz de un presente desesperanzador:

\begin{abstract}
Permanece absorta, perdida en la tarea de reordenar los fragmentos de aquel mapa familiar, pero al final se da cuenta de que las fotografías suplantan al legítimo recuerdo y, en últimas, la imagen que queda del pasado no es la que vive en la mente sino la que impone una foto. El fantasma de su padre, poco a poco, se ha ido borrando. Tan solo puede recordar momentos de esa vida perdida e irrecuperable [...]. El que vive en sus recuerdos es más real que el de las fotos. El de su mente está vivo, aunque esté muerto. Es ese recuerdo el que se niega a perder. Es ese al que busca. En el olor de las camisas viejas. En la música que tanto cantaba. En las piedras del río. El del álbum, solo sonríe; está quieto (pp. 52-53).
\end{abstract}

Aquí yace un aspecto importante que identifico como el mensaje tras el dilema de Delfina con las fotografías. En tanto recuerdo fabricado, no sostienen la memoria de su padre, porque para ella no es cierto que él resida allí, no cree en la mentira de la representación. Su pugna con las fotografías refleja la frustración que describe Barthes (2015) al intentar encontrar una imagen verídica de su madre en un cúmulo de fotografías; la esencia de su persona le evita, se le insinúa, pero no le puede llegar íntegra. Para esta joven, igual que para el crítico, las fotos bloquean la evocación pura en tanto que "imágenes parcialmente auténticas [...], por lo consiguiente, [son] totalmente falsas" (p. 107). Delfina libra una batalla consigo misma: entre la prueba de la existencia de su padre y la comprobación del desvanecimiento del recuerdo. El escenario de esta batalla es el álbum de fotografías, que contiene pruebas físicas de lo que ha sido, pero que resultan una quimera. La fotografía no miente acerca de la existencia de una persona, pero crea una falsa ilusión de permanencia en la cual ella repara. 
Resulta siempre más efectivo encontrar trazos verídicos de una persona en sus objetos personales, o como menciona Barthes (2015): "Para 'reconocer' a mi madre, [...] es necesario que, mucho más tarde, reconozca en algunas fotos los objetos que ella tenía sobre su cómoda” (p. 105). El recuerdo queda entonces anclado al presente por medio de los objetos que dan efectiva cuenta de la influencia física de una persona sobre su medio material, que se deja ver transparente en otra de las novelas de la Pentalogía de Ferreira. En Rebelión de los oficios inútiles el objeto material también se inscribe como el lugar de preferencia para hablar de la veracidad de una experiencia o de la efectiva existencia de alguna persona. Joaquín Borja, el protagonista, reflexiona: "De nada sirven las abstracciones que rezan: 'entre 500.000, 1.000.000, o acaso 6.000.000 de judíos fueron exterminados entre 1940-1945 [...] las estadísticas son lápidas sobre la amnesia y el olvido" (Ferreira, 2014, p. 37). La abstracción no sirve para la concepción de memoria que maneja este escritor. Para él, es más efectivo hablar de

Un museo no con sus cadáveres putrefactos sino con sus despojos, con sus objetos privados, secretos, con sus calzoncillos de la suerte que no llevaron, con sus camisas escotadas y agujereadas por los proyectiles, sus billeteras adornadas con fotos de sus esposas [...] convertir al muerto en lo que era, un padre, un hermano, un tío, un esposo, un ser humano que merecía vivir en la memoria ( $\mathrm{p}$. 37).

Esta podría ser la diferencia central entre un objeto empírico y un objeto representacional como objetos de memoria: la evidencia del artificio, de la creación de una memoria ex nibilo. Esta "performatividad mediática" y "enunciación política" (Richard, 2002, p. 55) podría encontrarse en los monumentos que se erigen en todo el mundo para conmemorar a las víctimas. Para el caso colombiano, el ejemplo más reciente de esta disyuntiva lo ubico en la obra Fragmentos (2018) de la artista colombiana Doris Salcedo, quien tomó las armas de la desmovilizada guerrilla de las FARC para fundirlas en el piso de una casa en el centro de Bogotá. Con respecto a esto, Nelly Richard (2002) apunta lícitamente que "la memoria debe seleccionar y montar, recombinar, los materiales inconclusos del recuerdo" y debe "Recoger estos fragmentos evitando la juntura forzada, profundizando más bien la desarmonía y el conflicto, en la aspereza de sus bordes, [lo cual] es una cuestión tanto ética como estética” (pp. 191-192). Evitar la juntura forzada es precisamente la operación 
contraria que se aprecia en Fragmentos. Todas las armas fundidas en una superficie homogénea, contradicen un discurso de una memoria plural. La pregunta que habría que hacerle a la obra es acerca del lugar donde queda el fragmento individual, si en la transformación material se contiene la certeza de los millones de balas que fueron disparadas por esos cañones, o los miles de cuerpos que fueron receptores de esas balas. En este sentido, el acceso a la memoria histórica concreta queda codificado por una abstracción que se "traduce en un aplanamiento de la imagen" (Boscagli, 2014, p. 188).

En el caso de Ferreira, la manera de representar la memoria histórica se aleja de las representaciones abstractas del pasado y en cambio se cimienta sobre la "aspereza de los bordes" del objeto, desde donde se desprende de su forma de construir personajes: a partir de la certeza de que un objeto material es más eficiente en dar cuenta de las personas que se evaporan en el remolino de la violencia, y del mensaje rotundo que sostiene en su materialidad una camisa vieja o un vestido ensangrentado. ${ }^{2}$ El borramiento de la identidad en favor de la aparición del objeto le confiere más dignidad a las víctimas porque en los objetos materiales pueden contenerse todas estas personas: hijos, padres, hermanos, esposos, sin necesidad de nombrarse y sin necesidad de generalizarse. Para la lógica de la Pentalogía hay más recuerdo en el rastro material que en el blanqueamiento de las infinitas imágenes desastrosas que componen la memoria colombiana en un piso de hierro.

El otro ejemplo de objeto representacional que quisiera mencionar es un gran fresco en la iglesia del pueblo. Si a través de Delfina la novela explora las conexiones con el pasado, en este capítulo examina las implicaciones del arte en el presente. "Una hoguera para que arda Goya” cuenta cómo Bernardo, el cura, y Enoc, el ebanista, entablan una cercana relación a causa de un encargo para pintar un mural en la iglesia, y cómo esto resulta en el ataque al pueblo por parte de los mercenarios. ${ }^{3}$ La figura del sacerdote, recurrente en la literatura de la Violencia colombiana, aparece en esta novela

2 Bajo la misma lógica de la serie de Ferreira opera Relicarios, de la artista colombiana Erika Diettes (2015). La memoria de las víctimas es tomada en la forma de sus objetos íntimos, sumergida en cubos de polímero de caucho y exhibida de forma reminiscente a la disposición de un cementerio. Es una reflexión directa y sin mediaciones de la violencia como hecho evidente, donde el objeto material ocupa, si se quiere, el lugar de la evidencia.

3 En la historia de Bernardo se esconden guiños a la figura de Camilo Torres, un cura colombiano que propugnó la teología de la liberación y terminó enlistándose en las filas del ELN en 1965. Murió a un escaso mes de haberse unido a esta guerrilla, en su primer enfrentamiento en el pueblo natal de Ferreira, San Vicente de Chucurí, Santander. 
como el punto de sinergia de los hechos narrados: como causante y culminación de la violencia. Alrededor de este personaje se concentra gran parte de las referencias a la historia del lugar y se enfatiza la voluntad de resistencia del pueblo campesino. Sobre este estado de cosas, el cura se ve forzado a "definirse de cara a la violencia que le rodea" (Pinillos, 1987, p. 218), y para hacer frente a esta situación, solo encuentra un camino:

\begin{abstract}
Ahora no iba a necesitar telones púrpura para Semana Santa, ni blancos inmaculados para la Cuaresma, ni escarlata festivo para Navidad, porque desde entonces luciría un fresco de dimensiones colosales, con escenas de tortura y martirio sobrepuestas en un mosaico desconcertante al estilo del Goya más caprichoso: la memoria y el inventario dibujado de los crímenes que se cometían a diario en la región y el trabajo más delicado de arte que le encomendaran jamás al ebanista Enoc, pero que el padre Bernardo no dudó en ordenar después de la matanza de campesinos durante el paro que terminó en tragedia, cinco años atrás (Ferreira, 2011, pp. 126-127).
\end{abstract}

Hay una evidente intención de denuncia en aquel objeto representacional. Y aquello que está representando allí es una imagen clara y estridente de la realidad del pueblo. El cura escoge el arte como su manera de posicionarse frente a los actores que antagonizan en el relato, y aquella decisión termina siendo determinante para el desarrollo de la trama:

El sacristán lo veía ponerse frente al mural y repasar con especial atención una pequeña escena representada en el extremo izquierdo de la pintura: la imagen de un hombre barbado y con la sotana a la usanza antigua que tenía un parecido explícito con el sacerdote. Cuatro encapuchados le apuntaban de muy cerca, como si pretendieran fusilarlo, y el hombre, con las manos atadas a la espalda, ofrecía esa mirada desafiante y dura a sus perpetradores, una mirada que denotaba más desdén que temor ante la muerte. [...] pasaba noches en vela fumando y oyendo Schubert y sumido en la contemplación de aquella fracción del mural, asombrado con la inexplicable ocurrencia de hallarse a sí mismo dibujado de pronto, ante el espectáculo de su propio fin (pp. 127-128).

Él sabe que lo van a matar por evidenciar la tragedia, y allí reside su gesto más revolucionario. Abre la puerta a la interpretación estética, y en ese espacio de incertidumbre deja inscrito su mensaje. $\mathrm{El}$ arte puede ser cualquier cosa en el marco de este relato: puede ser un capricho o una declaración de rebeldía. Así, este objeto representacional funciona como el detonante de todos los sucesos que ocurren al inicio de la novela, y simultáneamente se anticipa a estos. Porque a la vez que el mural se 
presenta como la herramienta que sostiene el pasado en el presente, muestra el futuro, creando con esto un amasijo de tiempos, fusionándolos sobre una sola superficie.

Ahora, sería apropiado decir que en este mural se esconde la gran metaimagen del relato. El sentido que este contiene es la historia de la masacre en el pueblo, que se devela en los capítulos de la novela, que contienen otros objetos materiales que ofrecen aún más sentidos que enriquecen la comprensión del hecho pintado. $Y$, aun así, la novela contiene al mural en el mismo nivel de realidad en que se encuentran los otros objetos que abundan en el relato, creando una especie de ciclo de representación. Para el presente de la lectura, la novela funciona como el mural para el presente de la narración: ambos objetos representacionales operan como denuncia pública, evidencian la tragedia que ha sido la constante en Colombia por décadas y la cual, si bien todos son conscientes de ella, quizá nadie alcanza a dimensionar debido a que las proporciones del crimen lo hacen inconcebible, y ni los supervivientes creen en los detalles del sufrimiento. No se trata de un esfuerzo incendiario, sino de un llamado a la reflexión.

Este objeto representacional resulta tan definitivo para el conjunto general de la novela porque no solo es el centro mismo de la representación, sino que se espeja completamente con la intención autoral detrás de la Pentalogía: recordar una vez más las manchas más ignominiosas del pasado nacional. La mejor crítica es la explicitación del hecho, y para este autor dicho problema queda resuelto con el objeto material. En una sociedad como la colombiana, cuya historia ha sido entorpecida por políticas de Estado que promueven el olvido, que desde entonces ha sido combatido con vehemencia desde diferentes áreas, el arte se posiciona como una de las formas más duraderas de hacer memoria, de ejercer resistencia. En palabras de Daniel Ferreira, su obra atiende a que

\begin{abstract}
Estamos constantemente olvidando. Mientras tanto, los gobiernos aprovechan la amnesia colectiva para acomodar el relato oficial y negar que ha sido el magnicidio, el oprobio, la tortura, el exterminio, el holocausto lo que decide el monopolio del poder. El arte se resiste y trabaja contra ese borrado natural y sistemático. Por eso está después de la memoria, no en lugar de la memoria. Tenemos pasado. Hay realidad. Hay hechos. Hay testigos. Hay memoria. Hay crónica. Hay historia. Hay historia madre. Y hay literatura. Esta trabaja con todo lo anterior y es indestructible (Citado en Guerrero, 2018).
\end{abstract}

De manera similar a la reflexión que alcanza con la historia de Delfina, este autor piensa su obra de la manera en que construye los objetos materiales que la habitan. 
Se preocupa por la concreción, por evitar el olvido en lo efímero; en pocas palabras: se interesa por la materialidad. Es sumamente significativo que los escritores contemporáneos tiendan a dejar que sus obras estén cada vez más habitadas por esta esfera de la experiencia vital; y para lo particular del presente caso, es una aproximación a formas alternativas y más concretas de hacer memoria.

Las apelaciones a la memoria son el ejercicio natural al que se aboca una literatura como la de Ferreira, y la atención de la novela por el resto material es un intento de asir la historia por sus partes menos volátiles. Pensando ahora la novela como un todo terminado, puede decirse que logra componer un mosaico de la guerra. A punta de detalles, el relato se desplaza por las generalidades hasta las subjetividades más profundas para mostrar múltiples visiones de una desgracia causada por odios centenarios. El relato ofrenda a la destrucción una cantidad indecente de cuerpos que quedan reverberando en el presente por la acción de sus restos materiales.

La lectura más superficial de esta obra no superaría el evidente sustrato histórico y la polifonía inscrita por la cantidad de voces para pensar la multiplicidad de perspectivas sobre el conflicto en Colombia. Sin embargo, la lectura desde el objeto material incluye todas estas concepciones y las sobrepasa, porque ya incluso desde la instancia de la frase, desplaza al sujeto como centro de la acción, enmarca y diferencia los tipos de personajes, sintetiza conflictos personales, historias nacionales, lleva el relato a su concreción y condensa de manera metarrepresentativa todo un argumento narrativo. Cada instancia narrativa configura sus objetos de formas particulares, lo cual hace del objeto material un elemento valioso a la hora de leer obras literarias.

Para concluir, es necesario aclarar que la aparición, incidencia y funcionamiento de los objetos materiales no es de ninguna manera sistemático ni predeterminado por mi propuesta de lectura. Las manifestaciones de la materialidad son específicas de cada obra y, como expliqué en los apartados anteriores, esconden rastros de significado de gran valor para el análisis literario. Los objetos materiales en otras novelas pueden estar dispuestos con organizaciones distintas, en mayor o menor cantidad que las que he analizado hasta aquí, y también podrían desarrollarse alrededor de centros temáticos diferentes. Aun así, la constante de análisis de mi propuesta es el enfoque en la agencia que tiene el objeto material sobre los hechos narrados, ya que en variadas instancias narrativas he encontrado que hay muchas historias paralelas y nuevos 
resquicios de sentido literario que se pasan por alto. Es claro que las conclusiones a las que he llegado aquí son a lo sumo preliminares, pero se mantiene la satisfacción de confirmar la existencia de sentido literario en algo que se piensa tan banal como una pistola heredada o un álbum de fotos.

\section{Referencias bibliográficas}

Bal, M. (1985). Teoría de la Narrativa (una introducción a la narratología). Madrid: Ediciones C. Barthes, R. (2015). La cámara lúcida: nota sobre la fotografía. Buenos Aires: Paidós.

Boscagli, M. (2014). Stuff Theory: Everyday Objects, Radical Materialism. New York: Bloomsbury.

Brown, B. (2015). Other things. Chicago: The University of Chicago Press.

Diettes, E. (2015). Relicarios. Medellín: Museo de Antioquia. Recuperado de: https://bit. ly/3fp1n6v [30.11.2019].

Ferreira, D. (2011). Viaje al interior de una gota de sangre. Bogotá: Alfaguara.

Ferreira, D. (2014). Rebelión de los oficios inútiles. Bogotá: Alfaguara.

Guerrero, M. (2018). Daniel Ferreira: "El arte trabaja contra el borrado natural de la memoria”. Revista Temporales. Recuperado de: https://bit.ly/2Y8i0hb [30.11.2019].

Holguín, C. (2015). Un santandereano impresentable e imprescindible. Arcadia, agostoseptiembre. Recuperado de: https://bit.ly/2YwIPKM [25.11.2019].

Mitchell, W.J. T. (1994). Picture Theory: Essays on Visual and Verbal Representation. Chicago \& London: University of Chicago Press.

Pinillos, Ma. de las N. (1987). El sacerdote en la novela de la guerrilla. En El sacerdote en la novela bispanoamericana (pp. 218-233). México D.F.: Universidad autónoma de México.

Richard, N. (2002). La crítica de la memoria. Cuadernos de literatura 8 (15), pp. 187-193.

Salcedo, D. (2018). Fragmentos. (Escultura). Bogotá: Museo Nacional de Colombia.

Velázquez, J. (2015). Heidegger o la metódica “destrucción” dentro de la fenomenología Husserliana. Investigaciones Fenomenológicas 5, pp. 331-343. 